This is the peer reviewed version of the following article:

V. Carrard, C. Bourquin, S. Orsini, M. Schmid Mast, \& A. Berney. Virtual patient simulation in breaking bad news training for medical students, Patient Educ. Couns. 103 (2020) 1435-1438.

which has been published in final form at https://doi.org/10.1016/j.pec.2020.01.019.

This manuscript version is made available under the CC-BY-NC-ND 4.0 license

https://creativecommons.org/licenses/by-nc-nd/4.0/ 


\section{Virtual patient simulation in breaking bad news training for medical students}

Valerie Carrard $^{\mathrm{a}}$, Céline Bourquin ${ }^{\mathrm{a}}$, Sandy Orsini ${ }^{\mathrm{a}}$, Marianne Schmid Mast ${ }^{\mathrm{b}}$, Alexandre Berney $^{\text {ac }}$

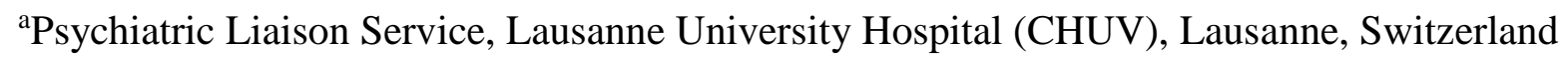

${ }^{b}$ Department of Organizational Behavior, University of Lausanne, Lausanne, Switzerland ${ }^{c}$ Corresponding author: Address: Avenue de Beaumont 23, 1011 Lausanne-CHUV, Switzerland; E-mail: Alexandre.Berney@chuv.ch; Tel: +41 21314 1105;

Fax: +41213141098

\section{Highlights}

- Virtual patient (VP) simulations are emerging tools to train medical communication.

- We tested a VP simulation as part of an undergraduate breaking bad news training.

- Focus groups with 23 medical students explored the utility of the simulation.

- The simulation trains technical skills and allows self-reflection on communication.

- The simulation is a valued add-on to lectures, simulated patient, and supervision. 


\begin{abstract}
Objective. The present study explores the use of a virtual patient (VP) simulation as part of a breaking bad news training in undergraduate medical education.

Methods. The VP simulation allows trying out and practicing different ways of disclosing a cancer diagnosis to a VP (avatar) and to react to emotionally-laden patient statements with the opportunity of self-observation through video recording. After testing the simulation, 23 students shared their experience in focus groups that were analyzed using thematic analysis.
\end{abstract}

Results. Self-observation is the most valued feature of the simulation, because it enables users to be aware of their behaviors and adjust them. The competences developed are otherwise technical (e.g., organization of information) and concern less interactional competences. Areas for improvement of the simulation are the interactivity, quality, and diversity of the VPs.

Conclusion. The findings show that VP simulations help develop technical communication competences and are best suited as add-ons to other forms of training, in which relational aspects can be targeted. Self-observation is especially valued because it allows for a critical view regarding one's own communication behaviors.

Practice Implications. The proposed simulation is beneficial as an add-on to lectures, supervision, and simulated patient interviews.

Keywords: undergraduate medical training; virtual patients; breaking bad news; communication training; qualitative analysis 


\section{Introduction}

Virtual patients (VPs) are computer-generated and manipulated graphical representation of a human (avatar) portraying patients in virtual environments used to train diverse medical competences such as making diagnosis or therapeutic decisions [1]. Recently, VP simulations have been developed to train complex communication competences such as breaking bad news $(\mathrm{BBN})[2-4]$, but these tools are in their infancy and more research is needed to understand their usefulness.

Nowadays, the importance of communication teaching is well established as a formal component of the medical curriculum in North America and Europe [5-7]. At our University, communication teaching is fully implemented with theoretical and practical courses throughout the medical curriculum. The present study focuses on our undergraduate BBN training consisting of a 45-min lecture and a 20-min videotaped training with a simulated patient (SP) for each student, followed by an individual 1-hour supervision with a faculty tutor (described elsewhere [8-10]).

Communication competence development needs first and foremost practice. SPs are largely recognized as a useful tool in this regard, but are resource-consuming. In the long run, VP simulation can be a cost-effective add-on to potentiate SP training. Indeed, it allows to train a notably stressful communication task [11] in a less worrisome context where mistakes are inconsequential. In that respect, our students consistently report the need to prepare for the SP encounters by writing down or role-playing the situation beforehand. VP simulation is a relatively accessible tool to prepare an SP encounter or any other patient encounter and can lower the anxiety related to such situations. VP simulations have indeed been shown to increase students' self-confidence [12] and self-efficacy [13] in the context of communication training. 
We built a VP simulation that allows for multiple trials of different ways to respond to emotionally-laden questions of patients in the context of an oncological BBN consultation and for self-observation through video recording. Consistent with previous recommendations $[1,14]$, the VP simulation is proposed as an optional add-on taking place after a lecture on general aspects of BBN and before the SP interview [8,9]. Before any implementation of such novel tool in the field of BBN training, it is essential to investigate the users' perspective to identify avenues of improvement. Thus, this short communication reports on a focus group study exploring the opportunities and limitations of a VP simulation add-on for undergraduate medical student training.

\section{Method}

Sixty-six fourth-year medical students recruited in class or via email in 2017 agreed to test the VP simulation. It consisted of an encounter with an on-screen 2D avatar portraying a patient to whom the students had to announce a terminal gastrointestinal cancer. The simulation was developed in the Vizard 5.7 platform, a python-based virtual reality programming language. During a scheduled session, the students sat in front of a computer equipped with a camera. After reading on-screen instructions about the medical case, they first chose one out of four avatar patients (young or old male, young or old female) and then selected the patient question they wanted to train or a trial in which the patient questions followed each other in the usual order of a consultation (see Table 1). A virtual medical consultation room then appeared on-screen. The student is sitting behind a virtual desk and the VP avatar walks into the room, sits down, and asks the question the student selected. Thereupon, the student responded to the VP while being videotaped. The VP showed attentiveness by displaying idle movements during the answer of the student but did not react otherwise to the answer. After having answered, the students stopped the recording, which was then saved automatically on the desktop of the computer. The student was free to repeat 
the same question as many times as wanted, to choose one of the other questions, or to watch the recorded answers. One training session typically took about $45 \mathrm{~min}$.

\section{Results}

Among the 66 students who tested the simulation, 23 (13M, 10F) participated in the follow-up focus groups (average duration: $60 \mathrm{~min}$ ). The focus groups were transcribed verbatim and analyzed with thematic analysis $[15,16]$. The four core themes reflect the research framework including pros, cons, and usefulness of the simulation. These themes and the data-driven subthemes are presented below and exemplified in Table 2.

\section{Theme A. Value}

The students reported on the usefulness of the simulation as a first experience of BBN, because they felt that there is always a benefit in having communication training opportunities available. They particularly highlighted the benefit of self-observation thanks to the video recording enabling them to have a critical view on their behavior. The students also noted the value of the simulation to train for SP encounters, communication competences exams, or real patient encounters. They described that the simulation was a stress-free situation that allows to organize their thoughts, to understand how to deal with sensitive topics, and to reflect on their communication.

\section{Theme B. Skills developed}

Students emphasized that the simulation enables the development of a range of communication skills such as observing their verbal and nonverbal communication, becoming more aware of their own reactions or nonverbal behaviors, and managing their emotional reactions, pauses, and silences. They mentioned that adapting to the patient thanks to the self-observation and being more cautious can be trained with the simulation.

\section{Theme C. Limitations}


The students noted that the VP simulation's impact is limited to the technical dimension of the communication (e.g., organization of the information, clarity of the language), whereas the interactional dimension (e.g., interactivity, empathy) could not really be trained. They thus questioned whether the VP simulation would really influence the SP encounter or ultimately real patient encounters (contradictory to a simulation's value reported previously). Moreover, the students mentioned potentially better alternatives such as role-playing in front of a camera.

\section{Theme D. Areas of improvement}

The areas of improvement were related to the lack of interactivity of the VPs, the limited diversity of the VPs' questions, and the organization of the VPs' questions (lack of flow between the questions), which precluded the realism of the situation and "immersion" according to the students' experience. Some students also noted that the simulation could be improved by indicating the "right" way of doing things (on-screen guidelines or examples of encounter) or by proposing a variety of scenarios with different medical situations or different levels of complexity in the interaction with the patient. The quality of the avatars (general look, gestures) and the virtual reality scope (more immersive simulation was expected) were also regarded as needing improvement.

\section{Discussion}

This exploratory investigation of a VP simulation to train BBN confirms findings of emerging literature in the field: such simulations are useful for the training of technical aspects of the medical communication, but less so for interpersonal aspects $[1,17]$. Thus, our study endorses that VP simulations are best suited as an add-on to and not a replacement of other forms of communication training such as lecture, SP interview, and supervision $[1,14]$. Especially in the latter forms of training, the affective and interactive aspects of BBN can be more effectively trained. Being in a virtual medical consultation room with VPs who ask 
emotionally-laden questions with human voices and show attentiveness is more engaging than just role-playing in front of a camera and enables the students to prepare their future $\mathrm{BBN}$ interviews by allowing multiple trials in a safe and stimulating environment. Moreover, our results confirm that the VP simulation is ideally placed before the SP interviews $[1,14]$.

Unexpectedly, the opportunity of self-observation through the videotaping was the most valued feature of the proposed VP simulation. It enabled students to have a critical view regarding their communication behaviors. Therefore, proposing self-observation in VP simulations might permit to go beyond the training of technical skills and foster reflection and auto-adjustment.

Another finding that emerged from our analysis is that students asked for good and/or bad examples or on-screen guidelines indicating the "right" way to answer patients' questions (Theme D). Our stance is to provide general landmarks to the BBN situation, but refrain from giving a communication recipe. We also encourage a flexible patient-centered approach, because it is well known that not all patients react positively to the same type of behaviors [18]. Adequately responding to the diversity of patients' needs asks for adaptation of communication and is not congruent with rigid guidelines [19]. This flexibility in communication could be experienced and trained by proposing a variety of VP scenarios.

\section{Conclusion}

Because our results underline the usefulness of the VP simulation, an online version accessible from any connected computer is currently being developed. Following students' feedback, the goal will be to put an emphasis on the self-observation and offer a variety of scenarios to train $\mathrm{BBN}$ communication.

\section{Practice Implication}

VP simulations allow to train BBN in a safe context where multiple trials can be made. They are valuable add-ons to more traditional communication training methods (e.g., lecture, 
SP encounter). The here-tested VP simulation enabled the students to develop technical skills and have a critical self-observation of their communication behaviors.

Acknowledgements: This work was supported by the 2016 Pedagogical Innovation Fund of the University of Lausanne, Switzerland. The authors thank Stephane Billeter for the development of the simulation.

Ethical consideration: The Human Research Ethics Committee of Canton de Vaud, Switzerland, certified that the study does not fall under the Human Research Act (HRA), hence does not require authorization from an ethics committee, since the focus was the training experience of medical students. In accordance with ethical principles of research, participants were informed of the study and provided written consent. No health information was recorded.

Conflict of interest statements: The authors declare no conflict of interest. 


\section{References}

[1] D.A. Cook, M.M. Triola, Virtual patients: A critical literature review and proposed next steps, Med Educ. 43 (2009) 303-11. https://doi.org/10.1111/j.1365-2923.2008.03286.x.

[2] F.W. Kron, M.D. Fetters, M.W. Scerbo, C.B. White, M.L. Lypson, M.A. Padilla, G.A. Gliva-McConvey, L.A. Belfore, T. West, A.M. Wallace, T.C. Guetterman, L.S. Schleicher, R.A. Kennedy, R.S. Mangrulkar, J.F. Cleary, S.C. Marsella, D.M. Becker, Using a computer simulation for teaching communication skills: A blinded multisite mixed methods randomized controlled trial, Patient Educ Couns. 100 (2017) 748-59. https://doi.org/10.1016/j.pec.2016.10.024.

[3] M. Ochs, G. De Montcheuil, J.-M. Pergandi, J. Saubesty, C. Pelachaud, D. Mestre, P. Blache, An architecture of virtual patient simulation platform to train doctors to break bad news, in: Conference on Computer Animation and Social Agents (CASA), 2017. https://hal.archives-ouvertes.fr/hal-01793374/ (accessed December 8, 2019).

[4] M. Ochs, P. Blache, G. de Montcheuil, J.-M. Pergandi, J. Saubesty, D. Francon, D. Mestre, A semi-autonomous system for creating a human-machine interaction corpus in virtual reality: Application to the ACORFORMed system for training doctors to break bad news, in: Proceedings of the Eleventh International Conference on Language Resources and Evaluation (LREC-2018), 2018. https://www.aclweb.org/anthology/L181467 (accessed December 8, 2019).

[5] D.H. Novack, G. Volk, D.A. Drossman, M. Lipkin, Medical interviewing and interpersonal skills teaching in US medical schools: Progress, problems, and promise, J Am Med Assoc. 269 (1993) 2101-5. https://doi.org/10.1001/jama.1993.03500160071034. 
[6] G. Makoul, T. Schofield, Communication teaching and assessment in medical education: An international consensus statement, Patient Educ Couns. 37 (1999) 191-5. https://doi.org/10.1016/S0738-3991(99)00023-3.

[7] M. Von Fragstein, J. Silverman, A. Cushing, S. Quilligan, H. Salisbury, C. Wiskin, UK consensus statement on the content of communication curricula in undergraduate medical education, Med Educ. 42 (2008) 1100-7. https://doi.org/10.1111/j.13652923.2008.03137.x.

[8] A. Berney, V. Carrard, M. Schmid Mast, R. Bonvin, F. Stiefel, C. Bourquin, Individual training at the undergraduate level to promote competence in breaking bad news in oncology, Psycho-Oncol. 26 (2017) 2232-7. https://doi.org/10.1002/pon.4452.

[9] A. Berney, C. Bourquin, Individual supervision to enhance reflexivity and the practice of patient-centered care: Experience at the undergraduate level, J Cancer Educ. 34 (2017) 363-5. https://doi.org/10.1007/s13187-017-1313-5.

[10] V. Carrard, C. Bourquin, F. Stiefel, M. Schmid Mast, A. Berney, Undergraduate training in breaking bad news: A continuation study exploring the patient perspective, PsychoOncol. Advance online publication (2019). https://doi.org/10.1002/pon.5276.

[11] O. Sarikaya, M. Civaner, S. Kalaca, The anxieties of medical students related to clinical training, Int J Clin Pract. 60 (2006) 1414-8. https://doi.org/10.1111/j.17421241.2006.00869.x.

[12] R. Sijstermans, M.W.M. Jaspers, P.M. Bloemendaal, E.M. Schoonderwaldt, Training inter-physician communication using the Dynamic Patient Simulator®, Int J Med Inform. 76 (2007) 336-43. https://doi.org/10.1016/j.ijmedinf.2007.01.007.

[13] A.D. Andrade, A. Bagri, K. Zaw, B.A. Roos, J.G. Ruiz, Avatar-mediated training in the delivery of bad news in a virtual world, J Palliat Med. 13 (2010) 1415-9. https://doi.org/10.1089/jpm.2010.0108. 
[14] M. Triola, H. Feldman, A.L. Kalet, S. Zabar, E.K. Kachur, C. Gillespie, M. Anderson, C. Griesser, M. Lipkin, A randomized trial of teaching clinical skills using virtual and live standardized patients, J Gen Intern Med. 21 (2006) 424-9. https://doi.org/10.1111/j.1525-1497.2006.00421.x.

[15] S. Wilkinson, Focus group research, in: Qualitative Research: Theory, Method and Practice, SAGE, 2004: pp. 177-99.

[16] J. Green, N. Thorogood, Qualitative methods for health research, SAGE, 2018.

[17] F. Consorti, R. Mancuso, M. Nocioni, A. Piccolo, Efficacy of virtual patients in medical education: A meta-analysis of randomized studies, Comput Educ. 59 (2012) 1001-8. https://doi.org/10.1016/j.compedu.2012.04.017.

[18] P.K. Graugaard, A. Finset, Trait anxiety and reactions to patient-centered and doctorcentered styles of communication: An experimental study, Psychosom Med. 62 (2000) 33-9. https://doi.org/10.1097/00006842-200001000-00005.

[19] V. Carrard, M. Schmid Mast, Physician behavioral adaptability: A model to outstrip a “one size fits all” approach, Patient Educ Couns. 98 (2015) 1243-7. https://doi.org/10.1016/j.pec.2015.07.028. 
Table 1.

Patient Questions of the VP Simulation

\begin{tabular}{|l|l|}
\hline Encounter phases & Questions \\
\hline 1. Diagnosis & $\begin{array}{l}\text { "The surgeon told me that he couldn't take all the tumor out, but I } \\
\text { am not sure I fully understood. Could you explain again the } \\
\text { situation to me?" }\end{array}$ \\
\hline 2. Treatment plan & $\begin{array}{l}\text { "I feel better since the surgery, do I have to do another } \\
\text { treatment?" }\end{array}$ \\
\hline 3. Prognosis & $\begin{array}{l}\text { "You say that I cannot be cured, so if I understand well, I must live } \\
\text { with it?" }\end{array}$ \\
\hline 4. Follow up & "I am really shocked, what will happen now?" \\
\hline
\end{tabular}


Table 2.

Themes, Subthemes, and Examples

\begin{tabular}{|c|c|}
\hline \multicolumn{2}{|l|}{ Theme A. Value } \\
\hline Usefulness of the simulation & $\begin{array}{l}\text { "It's a way of training communication. We do not have a lot of that." } \\
\text { "This is the introduction to the bad news [...] I learned this for the first time } \\
\text { and I was able to build on that for the next time, for the real stuff" }\end{array}$ \\
\hline Benefit of self-observation & $\begin{array}{l}\text { "Thanks to the video, there are still things that we can correct. Me, I know } \\
\text { that I made a first time and multiple times and every time I looked at myself, } \\
\text { I said to myself: 'No but it is not possible, you cannot say it like that, you } \\
\text { cannot do this head there when saying that, it is not possible! So I resume } \\
\text { and then I change that. This I think helped me." }\end{array}$ \\
\hline Train before an SP encounter & $\begin{array}{l}\text { "I think it helped me for the simulated patient. It really allowed me to have } \\
\text { a thread, know what I wanted to say, what I did not want to say. So it was a } \\
\text { good training." }\end{array}$ \\
\hline Train before the exams & $\begin{array}{l}\text { "Well, me, I still found quite useful before OSCEs [exams]. It forced me } \\
\text { revise and so, there, a little bit is not so bad!" }\end{array}$ \\
\hline $\begin{array}{l}\text { Train before an encounter } \\
\text { with a real patient }\end{array}$ & $\begin{array}{l}\text { "It helps to prepare for what can come and then be a little more } \\
\text { comfortable" } \\
\text { "It allows you precisely to pay attention to certain ways of saying things for } \\
\text { the day you do it with a patient" }\end{array}$ \\
\hline \multicolumn{2}{|l|}{ Theme B. Skills developed } \\
\hline $\begin{array}{l}\text { Observing verbal and } \\
\text { nonverbal communication }\end{array}$ & $\begin{array}{l}\text { "Regarding our gestures and our way of speaking, we often don't take a } \\
\text { step back except when looking at oneself." } \\
\text { "Sometimes we say things and we realize that it is not very adequate to say } \\
\text { it like that or not very understanding, that we do not understand well." }\end{array}$ \\
\hline $\begin{array}{l}\text { Becoming aware of our } \\
\text { reactions }\end{array}$ & $\begin{array}{l}\text { "The opportunity to see how we react to certain questions and then to say } \\
\text { to ourselves, honestly, I should have reacted maybe a little differently, I } \\
\text { would not like a doctor in front of me to react like that or things a little bit, } \\
\text { to visualize yourself how you react, yourself.." }\end{array}$ \\
\hline $\begin{array}{l}\text { Becoming aware of our } \\
\text { nonverbal behaviors }\end{array}$ & $\begin{array}{l}\text { "I might say caricaturally but [...] for some people, it could allow them to } \\
\text { become aware of their non-verbal behavior." }\end{array}$ \\
\hline $\begin{array}{l}\text { Managing our emotional } \\
\text { reactions }\end{array}$ & $\begin{array}{l}\text { "[Improving] our management of emotions because we either imagine } \\
\text { ourselves into it, we imagine ourselves as a doctor who announces a very } \\
\text { bad news to someone, I mean, we still feel something and then we try to } \\
\text { manage it. Then yes, it has less impact because it is virtual but it remains, } \\
\text { let's say, a first taste of what will happen later and then at least like that, } \\
\text { we are not let loose in this torrent of emotion and its variants." }\end{array}$ \\
\hline $\begin{array}{l}\text { Managing pauses and } \\
\text { silences }\end{array}$ & $\begin{array}{l}\text { "To realize that the silences we make, if we say nothing, it's not as long as } \\
\text { we imagine." }\end{array}$ \\
\hline $\begin{array}{l}\text { Adapting to the patient } \\
\text { thanks to the self-observation }\end{array}$ & $\begin{array}{l}\text { "To be able to record and see oneself that's very very good. [...] sometimes } \\
\text { we have mimics uh, eyebrows where, here, but well, that's how we are, but } \\
\text { it can help us learn to adapt a little and then adapt to the person that we } \\
\text { have in front of us. That's really good." }\end{array}$ \\
\hline Being more cautious & $\begin{array}{l}\text { "I could see that we could find other sentences [...] and then sometimes, } \\
\text { how we have a certain attitude with a type of sentence, well we can } \\
\text { modulate a little bit and then we can find formulations that are, perhaps } \\
\text { according to our personality, more tactful than others. Me, I found that, I } \\
\text { found it quite useful." }\end{array}$ \\
\hline
\end{tabular}

Note. The quotes have been translated from French by the first author VC. 
Table 2 (continued).

\begin{tabular}{|c|c|}
\hline \multicolumn{2}{|l|}{ Theme C. Limitations } \\
\hline $\begin{array}{l}\text { Limited to the technical } \\
\text { dimension }\end{array}$ & $\begin{array}{l}\text { "The simulation trains only the technical part of information giving. It's not } \\
\text { useless but it's just that for me, it only trains part of it." } \\
\text { "We are told to always explore the representations of the patient, what } \\
\text { worries him, what is important for him and there, well it is impossible." }\end{array}$ \\
\hline $\begin{array}{l}\text { No influence on the SP } \\
\text { encounter }\end{array}$ & $\begin{array}{l}\text { "Me, I wonder, if I had this simulation before my bad news delivers [with } \\
\text { the SP], whether it would have changed something in my interview or not. } \\
\text { And then, in the end, I think that it would have changed nothing to what I } \\
\text { had done during the interview. If I had been able to train, but maybe [...] I } \\
\text { would go there more serenely but, in the end, for the interview that I did, it } \\
\text { wouldn't have changed anything." }\end{array}$ \\
\hline Better alternatives & $\begin{array}{l}\text { "I told myself, all this program in the end we could do it with a sentence } \\
\text { that you give us and it would be much less complicated and then we film } \\
\text { ourselves with the camera [...] I think the development was important } \\
\text { enough to make all this program and then I have the impression that with a } \\
\text { piece of paper and then the camera, it would have been the same thing. It's } \\
\text { just that, well, I think all the work that it has implied to little avail." }\end{array}$ \\
\hline \multicolumn{2}{|c|}{ Theme D. Areas of improvement } \\
\hline Interactivity of the VPs & $\begin{array}{l}\text { "With a character a little without affects, a little static like that, it was I } \\
\text { find it hard to put some colors also to the interview and uh, I had rather the } \\
\text { impression to be in a theatrical role" } \\
\text { "We are still a little distant from the avatar to compare to someone real" }\end{array}$ \\
\hline Diversity of VPs' questions & $\begin{array}{l}\text { "There were four characters with the same scenarios so we did not really } \\
\text { see the point of having four characters" } \\
\text { "We could have exactly the same delivery of bad news but with different } \\
\text { questions from each avatar" }\end{array}$ \\
\hline $\begin{array}{l}\text { Organization of VPs' } \\
\text { questions }\end{array}$ & $\begin{array}{l}\text { "I found that when we could just choose one question [...] I quickly skipped } \\
\text { that, I did not really like [...] I thought it was not necessary to make each } \\
\text { separately" } \\
\text { "It's more real if everything is at once [the questions]" }\end{array}$ \\
\hline $\begin{array}{l}\text { Indicating the "right" way to } \\
\text { do }\end{array}$ & $\begin{array}{l}\text { "Seeing examples would very much help me. Like having a panel of 2-3 } \\
\text { interviews not necessarily very good or some very bad too. Just to have } \\
\text { landmarks." }\end{array}$ \\
\hline Variety of scenarios & $\begin{array}{l}\text { "Then there could be other situations, because I think it's a prototype but, } \\
\text { well, there is a cancer diagnostic, but there can also be other bad news to } \\
\text { break. It could also be a possibility. For instance, I don't know a diabetes } \\
\text { diagnosis." }\end{array}$ \\
\hline The quality of the avatars & $\begin{array}{l}\text { "I do not understand why, they [the avatars] were "badly done", because } \\
\text { today, we really have incredible possibilities [...] if one improved a little bit } \\
\text { the quality of the avatars, I think the emotions would be immediately better, } \\
\text { because there it's so much. Actually, they are a bit dented the avatars so it's } \\
\text { hard to really see the emotions and I think it influences a lot [...] since it's } \\
\text { all the time the same replicas and it does not interact with what we say, one } \\
\text { could videotape a person who says exactly what the avatar is saying and } \\
\text { then the person will look more realistic then we will have nothing to } \\
\text { program." }\end{array}$ \\
\hline The virtual reality scope & $\begin{array}{l}\text { "If I volunteered at the very beginning it's because I had the impression } \\
\text { that virtual reality was going to be actually really nice and entertaining." }\end{array}$ \\
\hline
\end{tabular}

Note. The quotes have been translated from French by the first author VC. 